\title{
Numerical Modeling of Cold Room's Hinged Door Opening and Closing Processes
}

\author{
R.Carneiro ${ }^{\text {a }}$, P. D. Gaspar ${ }^{\mathrm{a}}$, P. D. Silva ${ }^{\mathrm{a}}$ and L. C. Domingues ${ }^{\mathrm{a}}$ \\ ${ }^{a}$ University of Beira Interior, Edifício I das Engenharias, Calçada Fonte do Lameiro $n^{o} 1$, \\ Covilhã, 6201-001, Portugal \\ dinis@ubi.pt
}

\begin{abstract}
The need of rationalize energy consumption in agrifood industry has fasten the development of methodologies to improve the thermal and energy performances of cold rooms.

This paper presents a three-dimensional (3D) transient Computational Fluid Dynamics (CFD) modelling of a cold room to evaluate the air infiltration rate through hinged doors. A species transport model is used for modelling the tracer gas concentration decay technique. Numerical predictions indicate that air temperature difference between spaces affects the air infiltration. For this case study, the infiltration rate increases $0.016 \mathrm{~m}^{3} \mathrm{~s}^{-1}$ per $\mathrm{K}$ of air temperature difference. The knowledge about the evolution of air infiltration during door opening/closing times allows to draw some conclusions about its influence on the air conditions inside the cold room, as well as to suggest best practices and simple technical improvements that can minimize air infiltration, and consequently improve thermal performance and energy consumption rationalization.
\end{abstract}

Keywords: Numerical modeling, CFD, air infiltration, thermal performance, cold room, hinged door, tracer gas technique PACS: 02.60.-x; 47.11.-j; 89.40.Dd

\section{INTRODUCTION}

The food products refrigeration is associated with the need to preserve its quality. Temperature is one of the most important parameters of the inner conditions of cold rooms. Storage at appropriate temperatures according to the type of product increases substantially its lifespan from a few days until months (Stoecker, 1998). In the daily operation of any agrifood company is indispensable the repeated opening and closing of cold rooms doors for handling food products (storage or removal). This opening causes a natural convective airflow due to the pressure value difference between two rooms which is caused by temperature difference and hence of difference densities between the inside and outside air. Thus, the door opening and closing cycles for storing or removing of food products from cold rooms implies a thermal load associated to air infiltration. Several studies considered the development of analytical models to quantify the infiltration load over the time. Table 1 includes the empirical mathematical expressions to determine the air infiltration, $I\left[\mathrm{~m}^{3} \mathrm{~s}^{-1}\right]$.

TABLE (1). Analytical air infiltration models by natural convection through the door opening.

\begin{tabular}{cc}
\hline Authors/Year & Equation \\
\hline Brown and Solvason (1963) & $I=0.343 A(g H)^{0.5}\left[\frac{\rho_{\text {in }}-\rho_{\text {ext }}}{\rho_{\text {avg }}}\right]^{0.5}\left[1-0.498\left(\frac{b}{H}\right)\right]$ \\
\hline Tamm (1966) & $I=0.333 A(g H)^{0.5}\left[\frac{\rho_{\text {in }}-\rho_{\text {ext }}}{\rho_{\text {in }}}\right]^{0.5}\left(\frac{2}{1+\left(\rho_{\text {ext }} / \rho_{\text {in }}\right)^{0.333}}\right)^{1.5}$ \\
\hline Fritzsche and Lilienblum (1968) & $K_{f, L}=0.48+0.004\left(T_{\text {ext }}-T_{\text {in }}\right)$ \\
\hline Gosney and Olama (1975) & $I=0.333 K_{f, L} A(g H)^{0.5}\left[\frac{\rho_{\text {in }}-\rho_{\text {ext }}}{\rho_{\text {in }}}\right]^{0.5}\left(\frac{2}{1+\left(\rho_{\text {ext }} / \rho_{\text {in }}\right)^{0.333}}\right)^{1.5}$ \\
\hline Pham and Oliver (1983) & $I=0.221 A(g H)^{0.5}\left[\frac{\rho_{\text {in }}-\rho_{\text {ext }}}{\rho_{\text {in }}}\right]^{0.5}\left(\frac{2}{1+\left(\rho_{\text {in }} / \rho_{\text {ext }}\right)^{0.333}}\right)^{1.5}$ \\
\hline
\end{tabular}


CFD modelling has been progressively adopted by engineering due to its remarkable capabilities to predict details of fluid flow with heat and mass transfer. The study presented in this paper extends other studies using a 3D transient CFD model to evaluate the air infiltration rate into cold rooms during the opening and closing cycles of hinged doors. The influence of the air infiltration rate during the door opening/closing cycles on the inner air temperature of the cold room is evaluated by setting different values for the antechamber air temperature. Additionally, the influence of the air infiltration rate on the air temperature field variation inside the cold room relatively to a reference model, $T_{\text {in }}=273.15 \mathrm{~K}$ and $T_{\mathrm{ext}}=288.15 \mathrm{~K}$, for a hinged door typology (sensitivity analysis) is determined. The predictions of the numerical model for the reference case study are validated by comparison with results of analytical models shown in Table1. The novelty of the study is based on the use of the species equation for modelling the transport of a tracer gas. The tracer gas concentration decay method is used to determine the air infiltration rate through the hinged door of the cold room. The knowledge about the evolution of the air infiltration during the door opening/closing times, allows drawing some conclusions about its influence on the air conditions inside the cold room. Besides promoting the adoption and development of equipment with better efficiency, numerical models can be used to suggest costless best practices and simple technical improvements that can minimize air infiltration, and consequently improve thermal performance and energy consumption rationalization.

\section{MATERIALS AND METHODS}

This study required the development of a 3D transient CFD model of a cold room. The physical-mathematical formulation uses a set of coupled non-linear partial differential equations, describing mass, momentum and energy conservation, together with initial and boundary conditions. The finite volume method was used solve the mathematical model. The CFD Ansys Fluent code (Ansys, 2011) was used to implement both mathematical and numerical formulations. As the air infiltration is due to natural convection, the airflow regime was considered laminar and the fluid, air, behaves as an ideal and incompressible gas. The cold room model has a geometry approximated to a real case but with some assumptions to reduce the computational cost of the CFD model without affecting the quality and accuracy of results. The simulation times defined for door opening $(3 \mathrm{sec}$.), fully open $(8$ sec.) and closing $(3 \mathrm{sec}$.) periods were determined by Nunes et al. (2014). The 3D geometry (see Figure 1) consists of two adjacent rooms, the interior volume geometry (cold room), $V_{\text {in }}=96 \mathrm{~m}^{3}$, and the outside volume (antechamber), $V_{\mathrm{ext}}=128 \mathrm{~m}^{3}$. The door area is $A=1.2 \times 2.2 \mathrm{~m}^{2}$. The walls were considered adiabatic and the cold room is hermetic, because the focus of the study is the analysis of the natural convection fluid flow through the door opening.

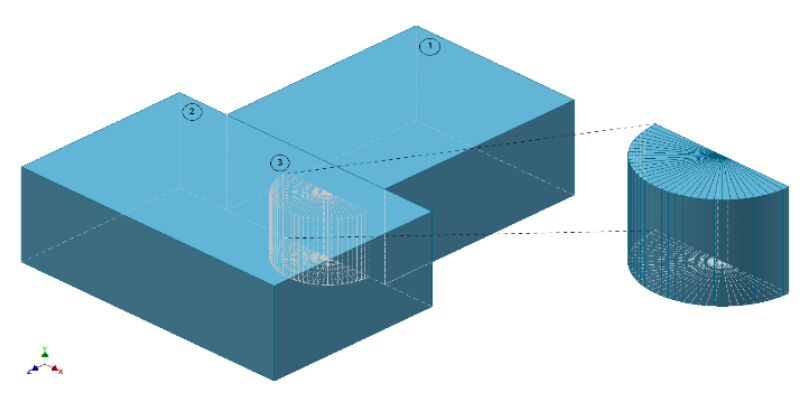

(a) Complete geometry (Legend: 1 - Cold room; 2 Antechamber; 3 - Door opening contour).

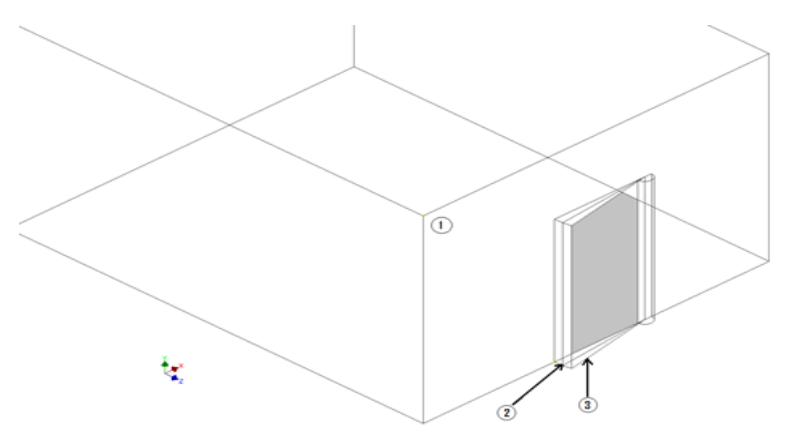

(b) Example of sliding door movement (Legend: 1 Cold room; 2 - Opening of $5^{\circ} ; 3$ - Opening of $10^{\circ}$.

FIGURE 1. 3D geometry of hinged door model.

For the region that represents the door, 36 individual geometries were created, where each of one corresponds to a different door position during the door opening/closing cycle in each time step ( $\Delta t=83.33 \mathrm{msec}$.). Therefore, for the hinged door the desired opening is $\theta=180^{\circ}$ which means that each of geometries has an arc of $\theta=5^{\circ}$. An unstructured mesh composed by 10,828,944 tetrahedral elements and 1,836,073 nodes was created. This type of mesh is proper to the geometry complexity and ensures a better refinement in regions where high gradients are expected. The species transport model is one of the most important in this numerical model since it allows defining a mixture of "air + tracer gas". The new fluid, "tracer", has the same properties of air. The model is used to set the species transport depending on pressure variations. The tracer gas concentration decay technique involves in practice the injection of predetermined concentration, $C_{1}$, of a tracer gas inside a hermetic room. This value, the 
final concentration after setting an opening, $C_{2}$, and the time between measurements, $t$, allow calculating the air infiltration rate, $I$, in the cold room of volume, $V$, using eq. (1) as described by ISO 12569:2012 or ASTM E741-11 standards.

$$
I=\frac{V}{t} \ln \left(\frac{C_{1}}{C_{2}}\right)
$$

\section{RESULTS AND DISCUSSION}

The sensitivity analysis determines the effect of air temperature outside the cold room on the air infiltration rate. First, the simulation of the reference model was performed, which air temperature outside the cold room is $T_{\text {ext }}=$ 288.15 K. Subsequently, two models that consider a variation of $1 \mathrm{~K}$ of the air temperature value outside the cold room, i.e., $T_{\text {ext }}=287.15 \mathrm{~K}$ and $T_{\text {ext }}=289.15 \mathrm{~K}$ were developed. Figure 2 shows the air temperature field along all computational domain and the tracer gas flow at two different instants.
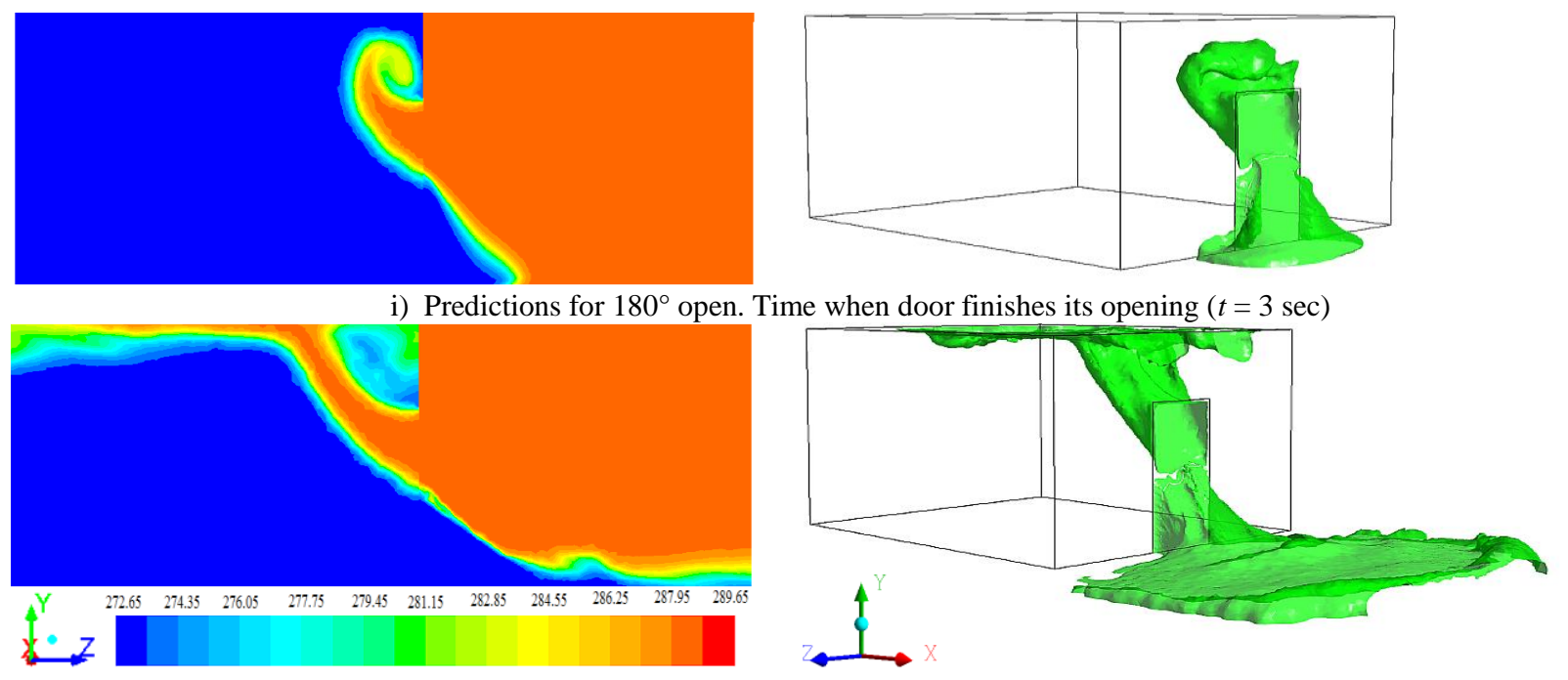

ii) Predictions for $180^{\circ}$ open. Time when door starts to close after being opened $8 \mathrm{sec}(t=11 \mathrm{sec})$

(a) Temperature field (K) in $y z$ plane, $x=2750 \mathrm{~mm}$

(b) Iso-surface of tracer gas concentration of $0.25 \%$

FIGURE 2. Numerical predictions for hinged door model (reference case study).

A neutral pressure line is predicted above which the hot air flows from the external environment into the cold room. This condition occurs due to the faster decreasing pressure inside the cold room than in the outside (see Figure 2). The air flows in opposite direction, from the interior to the exterior of the cold room, below the neutral pressure line. This condition is due to the faster increase of the pressure inside the cold room than in the outside. The numerical predictions of the profile of the air infiltration rate during the door opening/closing cycle for different air temperatures outside the cold room are analysed. The results suggest that higher the difference of air temperature between two rooms, higher is the air infiltration rate at each time step. The results show that, on an average, for each $\mathrm{K}$ of air temperature increase outside the cold room (or air temperature difference between two rooms), the air infiltration rate through the door opening increases $\Delta I=0.016 \mathrm{~m}^{3} \mathrm{~s}^{-1}$ i.e., 16 liters $\mathrm{s}^{-1}$, considering a hinged door with an area $A=2.62 \mathrm{~m}^{2}$. A similar analysis can be performed concerning the average air temperature inside the cold room. On average, for each $\mathrm{K}$ of air temperature increase outside the cold room (or air temperature difference between two rooms), the air temperature inside the cold room increases $\Delta T_{\text {in }}=0.10 \mathrm{~K}$. The comparison between air infiltration rate through the door opening based on numerical model predictions (reference model) and as calculated by analytical models (see Table 1) are shown in Figure 3. In general, the numerical model underestimate the air infiltration rate, except when it is compared with Fritzsche and Lilienblum model (1968) since it is overrated. On the other hand, analytical models do not consider the hinged door operating movements. From the first movement of the door, corresponding to $\theta=5^{\circ}$, the exposed area to air infiltration is equal to the total opening area $\left(A=2.64 \mathrm{~m}^{2}\right)$. Thus, although the door constitutes a barrier to the air flow, it is not accounted in the analytical models since they only consider the opening area changing, then the air infiltration rate is constant during all door operation movement. 


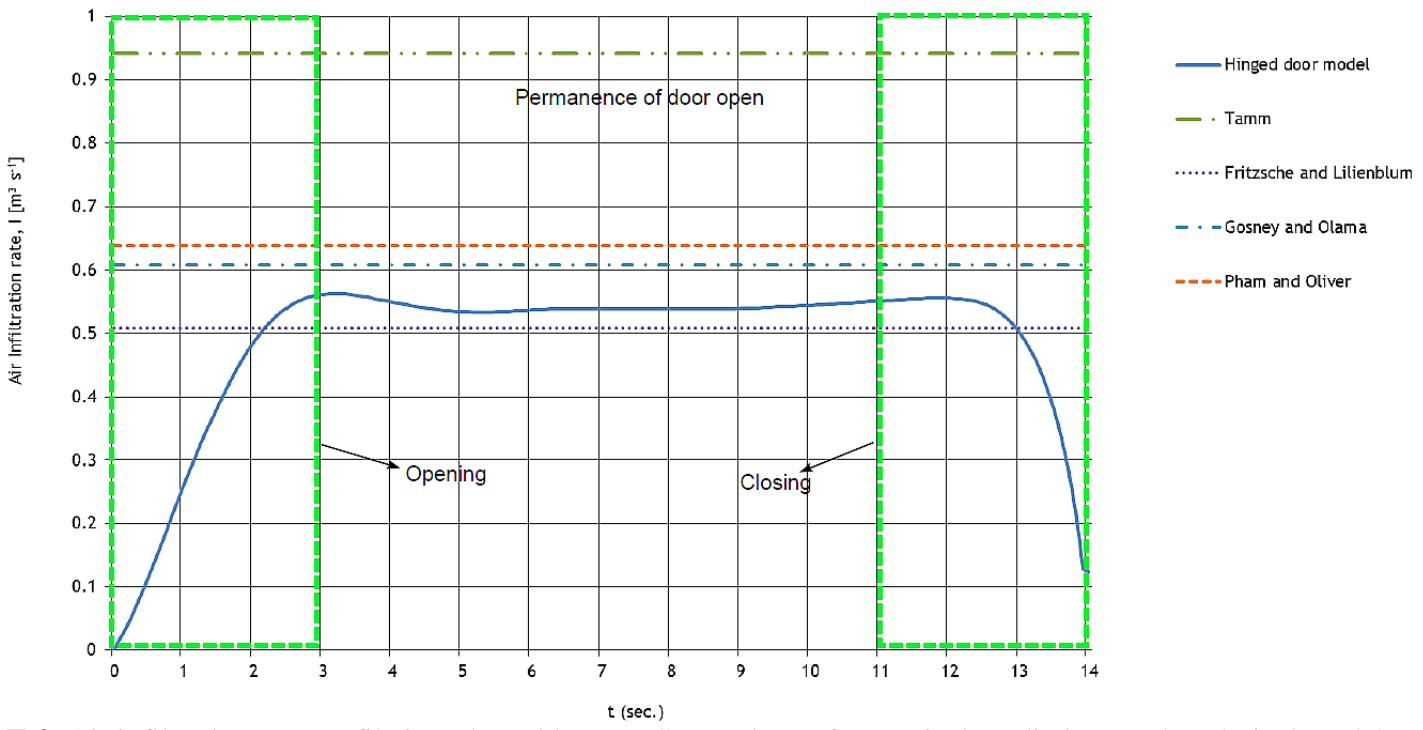

FIGURE 3. Air infiltration rate profile into the cold room: Comparison of numerical predictions and analytical models results.

\section{CONCLUSIONS}

This paper presents the 3D transient CFD modelling of a cold room to evaluate the air infiltration rate through hinged doors. The novelty of this study is based on the use of the species equation for modelling the transport of a tracer gas. The tracer gas concentration decay method is used to determine the air infiltration rate through the sliding door of the cold room. A sensitivity analysis of the air infiltration rate during the hinged door opening/closing cycles on the inner air temperature of the cold room is performed by varying the value of the antechamber air temperature by $1 \mathrm{~K}$ relatively to the reference case study $\left(T_{\mathrm{in}}=273.15 \mathrm{~K}\right.$ and $\left.T_{\text {ext }}=288.15 \mathrm{~K}\right)$. The results show that, on average, for each $\mathrm{K}$ of air temperature increase outside the cold room (or air temperature difference between two rooms), the air infiltration rate through the door opening increases 16 liters $\mathrm{s}^{-1}$ and consequently the air temperature inside the cold room increases $0.10 \mathrm{~K}$, for a sliding door with an area of $2.64 \mathrm{~m}^{2}$. The air temperature inside the refrigerated space is affected by the door opening/closing cycles that lead to warm air infiltration into the cold room. Thus, its evaluation and quantification may promote actions and solutions to reduce the operating frequency of the refrigeration system, and consequently the reduction of energy consumption and longer products safety. The numerical predictions obtained for the air infiltration rate through the door opening indicate that it has a variation profile over the time depending on the opening area, while the analytical models results admit it as being permanent. The comparison of these numerical model predictions with the results of the most precise analytical models allowed concluding that the numerical model predicts accurately the air infiltration rate.

\section{REFERENCES}

1. W. F. Stoecker, Industrial Refrigeration Handbook, New York, McGraw-Hill, 1998.

2. W. G. Brown and K. R. Solvason, Natural convection in openings through partitions-1, vertical partitions. Int. J. Heat Mass Tran. 5, 859-868 (1963).

3. W. Tamm, Kalterveluste durch kuhlraumoffnungen, Kaltetechnik-Klimatisierung 18, 142-144 (1966).

4. C. Fritzsche and W. Lilienblum, Neue Messungen zur Bestimmung der Kälteverluste an Kühlraumtüren. KältetechnikKlimatisierung 20, 279-286 (1968).

5. W. B. Gosney and H. A. L. Olama, "Heat and enthalpy gains through cold room doorways". In Proceedings Institute of Refrigeration, 72, 1975, pp. 31-41.

6. Q. T. Pham and D. W. Oliver, "Infiltration of air into cold stores". In Proceedings of 16th International Congress of Refrigeration, 4, 1983, pp. 67-72.

7. Ansys, Ansys Fluent 14 User's Guide, 2011.

8. ASTM, ASTM E741-11: Standard Test Method for Determining Air Change in a Single Zone by Means of a Tracer Gas Dilution. ASTM Standard, 2011.

9. ISO, ISO 12569:2012: Thermal performance of buildings and materials -- Determination of specific airflow rate in buildings -- Tracer gas dilution method. International Organization for Standardization (ISO), 2012.

10. J. Nunes, D. Neves, P. D. Gaspar, P. D. Silva and L. P. Andrade, L.P, Predictive tool of energy performance of cold storage in agrifood industries: The portuguese case study. Energy Conversion and Management 88, 758-767 (2014). 